\title{
Inhalation drug delivery devices: technology update
}

This article was published in the following Dove Press journal:

Medical Devices: Evidence and Research

12 February 2015

Number of times this article has been viewed

\section{Mariam Ibrahim \\ Rahul Verma \\ Lucila Garcia-Contreras}

Department of Pharmaceutical Sciences, College of Pharmacy,

The University of Oklahoma Health Sciences Center, Oklahoma City, OK, USA
Correspondence: Lucila Garcia-

Contreras

Department of Pharmaceutical Sciences, College of Pharmacy, The University of Oklahoma Health Sciences Center, Oklahoma City, OK 73I 26-090I, USA

$\mathrm{Tel}+$ I 405 27| 6593 ext 47205

Fax + I 405 27| 7505

Email lucila-garcia-contreras@ouhsc.edu
Abstract: The pulmonary route of administration has proven to be effective in local and systemic delivery of miscellaneous drugs and biopharmaceuticals to treat pulmonary and nonpulmonary diseases. A successful pulmonary administration requires a harmonic interaction between the drug formulation, the inhaler device, and the patient. However, the biggest single problem that accounts for the lack of desired effect or adverse outcomes is the incorrect use of the device due to lack of training in how to use the device or how to coordinate actuation and aerosol inhalation. This review summarizes the structural and mechanical features of aerosol delivery devices with respect to mechanisms of aerosol generation, their use with different formulations, and their advantages and limitations. A technological update of the current state-of-the-art designs proposed to overcome current challenges of existing devices is also provided.

Keywords: pulmonary delivery, asthma, nebulizers, metered dose inhaler, dry powder inhaler

\section{Introduction}

Inhalation therapy has been used for thousands of years, albeit in a different form and use. Inhalation therapy was practiced by ancient civilizations in Egypt, Greece, India, and People's Republic of China as evidenced by different artifacts displayed in museums, that may be considered the first used inhalation devices. ${ }^{1,2}$

Currently, inhalation therapy is the best option for lung diseases like asthma, cystic fibrosis, and chronic obstructive pulmonary disease (COPD). These local therapies allow the use of smaller doses and reduce systemic side effects. ${ }^{3}$ In the last two decades, a remarkable scientific interest in the technology for pulmonary delivery was spiked by the fact that the lungs can be used as a portal for systemic drug delivery. ${ }^{4}$ Pulmonary delivery is attractive as a route for systemic administration due to fast absorption by the massive surface area of the alveolar region, the abundant vasculature and thin air-blood barrier, and the avoidance of first pass metabolism. ${ }^{5}$ The effectiveness of an aerosol therapy is largely dependent on how much of the medication will reach the intended site of deposition. ${ }^{6}$ The deposition pattern of the administered aerosol is determined mainly by the formulation and the delivery device. Devices used to deliver therapeutic agents as aerosols are based on one of the three platforms: nebulizers, pressurized metered-dose inhaler (pMDI), and dry powder inhalers (DPIs). This review provides a description of the conventional and the current state-of-the-art design for inhaler devices and how this has improved the performance of these devices. 


\section{Basic principles of particle deposition to the respiratory tract}

In order to understand the reasons behind the design of each inhaler and to assess the performance of devices currently in use, one has to understand the basic principles of drug deposition in the lung, factors that can influence the deposition pattern, and how these affect the therapeutic outcome of the inhaled treatment. Table 1 provides the parameters that should be considered in designing aerosol delivery devices. ${ }^{7,8}$

The mass median aerodynamic diameter and geometric standard deviation (GSD) are what determine the site of deposition in the respiratory tract. Large particles or droplets deposit by impaction in the upper respiratory tree of the lung (oropharyngeal and tracheo-bronchial region), where air velocity is high and the air flow is turbulent. ${ }^{9,10}$ Particles in the size range of $0.5-5 \mu \mathrm{m}$ deposit by sedimentation in the terminal bronchioles and alveolar regions. The larger the GSD, the mores sites that the aerosol will be deposited in the respiratory tract. In general, aerosols with GSD $<2$ are desirable and ideally, aerosol particles should be as close as possible to monodispersity to increase deposition at the desired site of action and increase the efficacy of the treatment. ${ }^{11}$ Since a detailed discussion of these topics is beyond the scope of this review, readers are encouraged to revise these concepts elsewhere. ${ }^{12}$

\section{Challenges that patients face with current inhaler devices}

The major problems with the use of inhaler devices are the deposition of aerosolized particles in the oropharyngeal region and upper airways and the lack of coordination

Table I Parameters to be considered when designing an effective inhaler

\begin{tabular}{ll}
\hline Properties & Parameters \\
\hline Aerosol properties & Mass median aerodynamic diameter \\
& Geometric standard deviation \\
& Fine particle fraction \\
& Air/particle velocity \\
& Volume diameter \\
Particle properties & Bulk density \\
& Tap density \\
& Shape \\
& Charge \\
Physicochemical & Solubility \\
properties & Hygroscopicity \\
Lung properties & Geometry of respiratory tree (airway \\
& structure and diameter of airways) \\
& Influence of disease state on airway structure \\
& Breathing pattern - mouth or nasal breathing \\
\hline
\end{tabular}

between the device activation and inhalation due to lack of patient training. 13,14

In general, pMDIs generate aerosol faster than the patient can inhale. Coordination between device actuation and patient inhalation is especially difficult in children and the elderly. With some DPIs, it is required that the patient inhales at maximum force to disperse then inhale the powder, which unless properly trained, is rarely achieved. ${ }^{15}$ In these scenarios, most of the aerosol deposits in the upper airways. For pMDIs, this problem was addressed by providing a spacer or by designing breath-activated inhaler instead of breathcoordinated devices. ${ }^{16}$

The effectiveness of pulmonary delivery is also dependent upon the breathing pattern of the patient. Rapid inspiration is not recommended when using pMDIs and nebulizers, since it creates a turbulent air flow and fast velocity which increases the deposition by impaction in the upper airways. ${ }^{17}$ However, rapid inspiratory air flow is required to deagglomerate drug particles for inhalation in DPI devices. ${ }^{18}$ Medical personnel should train the patients when the device for their medication is changed. For a proper aerosol deposition, patients are advised to take a deep initial breath, and then hold it for 10 seconds to allow for the aerosol to settle down in small bronchioles and the alveolar region.

\section{Nebulizers}

There are two types of nebulizers, jet and ultrasonic, that differ in the force used to generate the aerosol from the respective liquid. Depending on the model and the manufacturer, nebulizers generate $1-5 \mu \mathrm{m}$ droplets. Nebulizers do not require patient coordination between inhalation and actuation, thus they are useful for pediatric, elderly, ventilated, non-conscious patients, or those who are unable to use pMDIs or DPIs. Nebulizers have the capability of delivering larger doses compared to the other aerosol devices even though this will require longer administration times. ${ }^{19}$

Jet nebulizers are based on Venturi's principle which states that fluid pressure decreases as its passes through a narrow sectional area. In these nebulizers, air stream moves through a small capillary tube at high velocity creating a low pressure that drives the liquid to be aerosolized up the capillary tube..$^{20}$ The high velocity blast of air carrying the droplets will bump into baffles placed in different numbers and positions depending on the design of the jet nebulizer. The impaction of large droplets on these baffles either break them into smaller sized droplets that will leave the nebulizer or will retain them in the device to be re-nebulized until their size is small enough to leave the nebulizer. Baffles also reduce 
the velocity of the aerosol cloud emitted from the nebulizer, which reduces impaction in the oropharyngeal region when inhaled by the patient. The main issues with jet nebulizers are the requirement for a sometimes cumbersome compressor to generate the aerosol, the noise that some of them generate ${ }^{21}$ and the temperature drop of the liquid in the nebulizer chamber due to liquid evaporation in the nebulized droplets. ${ }^{21}$

In ultrasonic nebulizers, sound waves are created due to the vibration of piezoelectric crystals at high frequency, creating crests that break the liquid into small droplets. Ultrasonic nebulizers are not completely portable because they still need electric supply for charging. Compared to jet nebulizers, ultrasonic nebulizers are more expensive and tend to increase the temperature of the nebulized drug solution; thus they are considered inappropriate to nebulize thermolabile peptides or DNA. They are also less efficient in nebulizing viscous liquids and suspensions than jet nebulizers, probably because of the reduced force that is used to atomize the liquid. ${ }^{22,23}$

From the device perspective, the variables that need to be optimized to emit an accurate and consistent dose with the nebulizer are: 1) the volume of the drug solution that is loaded in the device (taking into account its "dead volume"); 2) the viscosity of the drug solution; 3 ) the air flow and pressure in case of jet nebulizers; and 4) the tubing, mask, or mouthpiece used. In unoptimized therapies, a large proportion of the emitted dose from the nebulizers may be lost in the tubing, may remain as "the dead volume", or be lost in the surrounding area in case of unvented nebulizers, exposing others to the aerosol. The lack of optimization of these variables is the main source of dose variability that a patient may receive. A disadvantage for the users of nebulizers is that they have to be assembled and loaded with the medication before each use. Then they have to be de-assembled and cleaned if they are to be reused. ${ }^{5}$ All these steps may be hard to follow for an untrained-young/elderly patient.

From the formulation perspective, liquid formulations used in nebulizers are cheaper and easier to develop compared to formulations used in pMDIs and DPIs. Also, different compatible drug solutions can be mixed and nebulized concurrently. However, it is important to alert users that the droplet size and the dose emitted by a particular device can be altered by a change in the viscosity of the solution and that nebulizer settings should be optimized for each medication.

\section{Technological advances in nebulizers}

Table 2 lists some of the newest nebulizer models in the market. These include breath-enhanced, breath-actuated, and vibrating mesh nebulizers.
The design of breath-enhanced jet nebulizers such as the Pari $\mathrm{LC}^{\circledR}$ jet plus nebulizer is modified to allow for air entrainment during inspiration and to vent the expired air outside of the device. The main advantage of this approach is to increase the output rate, which in turn will decrease the administration time. ${ }^{21}$ However, in another study done by Pitance et al has shown that an unvented standard jet nebulizer with a corrugated extension tubing attached to the expiratory side of the T-shaped piece achieved higher drug levels than vented nebulizers. ${ }^{24}$

Breath-actuated nebulizers such as the AeroEclipse ${ }^{\circledR}$ emit aerosolized droplets only when the patient inhales. Therefore, no drug is wasted during exhalation as the case of regular jet nebulizers and dissemination of expensive or toxic drugs to the surrounding environment is avoided.

Vibrating mesh nebulizers such as Pari eFlow ${ }^{\circledR}$ rapid and Omron U22 have a mesh plate that, when it vibrates through the action of the piezoelectric element, breaks the liquid into very fine droplets, which increases the volume of aerosol deposited in the alveoli. ${ }^{15}$ Smaldone and Sagalla showed ${ }^{25}$ that the Omron U22 vibrating mesh nebulizer significantly reduces the residual drug remaining in the nebulizer compared PARI LC ${ }^{\circledR}$ jet plus or Respironics SideStream ${ }^{\circledR}$ jet nebulizers. This is especially advantageous for expensive medications. Perhaps the most advanced and efficient vibrating mesh nebulizer is the AKITA2 ${ }^{\circledR}$ APIXNEB. It has an electronic indicator that shows when the patient is breathing

Table 2 Examples of nebulizers with novel technologies

\begin{tabular}{|c|c|c|c|}
\hline Nebulizer & Type & Company & References \\
\hline $\begin{array}{l}\text { AeroEclipse }{ }^{\circledR} \text { II } \\
\text { BAN }\end{array}$ & $\begin{array}{l}\text { Breath-actuated } \\
\text { jet nebulizer }\end{array}$ & $\begin{array}{l}\text { Monaghan } \\
\text { Medical } \\
\text { Corporation }\end{array}$ & 23,28 \\
\hline $\begin{array}{l}\text { AKITA }^{2} \\
\text { APIXNEB }\end{array}$ & $\begin{array}{l}\text { Vibrating mesh } \\
\text { nebulizer }\end{array}$ & $\begin{array}{l}\text { Activaero } \\
\text { GmbH }\end{array}$ & 16,29 \\
\hline $\begin{array}{l}\text { CompAIR TM } \\
\text { NE-C80I }\end{array}$ & $\begin{array}{l}\text { Jet nebulizer } \\
\text { with virtual valve } \\
\text { technology }\end{array}$ & $\begin{array}{l}\text { OMRON } \\
\text { Healthcare } \\
\text { Europe BV }\end{array}$ & 30 \\
\hline $\begin{array}{l}\text { I-neb AAD } \\
\text { System }\end{array}$ & $\begin{array}{l}\text { Vibrating mesh } \\
\text { nebulizer with } \\
\text { metering chambers } \\
\text { and adaptive aerosol }\end{array}$ & $\begin{array}{l}\text { Koninklijke } \\
\text { Philips NV }\end{array}$ & 22,31 \\
\hline $\begin{array}{l}\text { Micro Air }{ }^{\circledR} \\
\text { NE-U22 }\end{array}$ & $\begin{array}{l}\text { Vibrating mesh } \\
\text { nebulizer }\end{array}$ & $\begin{array}{l}\text { OMRON } \\
\text { Healthcare } \\
\text { Europe BV }\end{array}$ & 32 \\
\hline PARI LC ${ }^{\circledast}$ Plus & $\begin{array}{l}\text { Breath-enhanced } \\
\text { jet nebulizer }\end{array}$ & $\begin{array}{l}\text { PARI } \\
\text { international }\end{array}$ & 33,34 \\
\hline $\begin{array}{l}\text { PARI eFlow }{ }^{\circledR} \\
\text { rapid }\end{array}$ & $\begin{array}{l}\text { Perforated } \\
\text { oscillating } \\
\text { membrane }\end{array}$ & $\begin{array}{l}\text { PARI } \\
\text { international }\end{array}$ & 33 \\
\hline $\begin{array}{l}\text { SideStream } \\
\text { Plus }\end{array}$ & $\begin{array}{l}\text { Breath-enhanced } \\
\text { jet nebulizer }\end{array}$ & $\begin{array}{l}\text { Koninklijke } \\
\text { Philips NV }\end{array}$ & 25 \\
\hline
\end{tabular}


appropriately and only then, it releases the dose, with droplet size of mass median aerodynamic diameter $<4 \mu \mathrm{m}$ and minimum drug loss $(\sim 1 \%) .{ }^{26} \mathrm{I}$-neb is also another example of vibrating mesh nebulizer coupled with an adaptive aerosol delivery software that adjusts the aerosol emission based on the breathing pattern of the patient, which reduces drug loss and increases the inhaled mass. ${ }^{27}$ This smart device can adjust the dose delivery based on last three breaths and provides feedback after dose delivery. ${ }^{15}$

\section{Pressurized metered-dose inhalers}

pMDIs are the most popular inhalers to treat local respiratory diseases such as asthma and COPD. The structural components of the conventional pMDI are the canister, metering valve, actuator, and a mouth piece. ${ }^{35}$ Canisters are made of inert materials capable of enduring the high pressures required to keep the propellant gas in liquid state. Plastic, stainless steel, glass, and aluminum have been used to make canisters. ${ }^{36}$

The metering valve is designed to deliver a precise aerosol amount $(20-100 \mu \mathrm{L})$ each time the device is actuated. When the inhaler is not used, an inner valve between the canister and the meter chamber is open allowing the chamber to be filled with the propellant-drug mixture in liquid form. At the same time, another outer valve between the meter chamber and the outside air is closed. As the patient presses the canister for dose actuation, the inner valve closes while the outer valve opens releasing the metered drug-propellant mixture retained in the chamber through the actuating orifice in an aerosol form. . $^{37,38}$

Internally, the actuator includes the spray nozzle (actuator orifice) and the expansion chamber in which the released propellant from the metering chamber expands and partially volatizes due to the decrease in pressure. The design of the actuator significantly influences the performance of pMDIs. Smyth has shown that the diameter of both the actuator orifice and the expansion chamber in addition to the orifice jet length affects the spray pattern and the emitted particle size. Newer actuators are equipped with a dose counter that indicates the number of doses remaining. ${ }^{39}$

\section{Formulation of pMDIs}

pMDIs drug formulations can be solutions or suspensions in a single propellant or propellant mixture and may include excipients such as ethanol or surfactants to solubilize the drug or stabilize a drug suspension. ${ }^{40}$ Recently, the use of pMDIs has extended beyond bronchodilators and corticosteroids to deliver proteins, ${ }^{41}$ plasmid DNA, ${ }^{42}$ and live attenuated virus vaccines or bacteriophages. ${ }^{43}$
Ideally, propellants should be nontoxic, non-flammable, and compatible with the formulation and provide consistent vapor pressure during the entire life of the product. Chlorofluorocarbons, were used as propellants in pMDIs for decades $^{36}$ but had deleterious effects including ozone layer depletion. After their mandatory ban by the Montreal Protocol, chlorofluorocarbons were replaced by hydrofluoroalkane (HFA) propellants in all pMDIs except for those in People's Republic of China. ${ }^{44}$ However, reformulating pMDIs with HFA propellants was challenging, often needing to use new excipients and metering valves. ${ }^{40}$

\section{Technological advances of pMDls}

New pMDIs can be classified as breath-actuated or coordination devices. Breath-actuated pMDIs, such as the Easibreathe $^{\circledR}$, were designed to address the problem of poor coordination between inhaler actuation and patient's breathe. These mechanical devices are activated when the device senses the patient's breathe and emits the dose in response. ${ }^{45,46}$ Breathe coordinated pMDIs were developed to synchronize the inspiration with the discharge of the dose from inhaler. The inhalation flow rate is coordinated through the actuator and the patient gets time to actuate the pMDI reliably during inhalation. ${ }^{40}$

A clever approach was proposed by Kelkar and Dalby to reduce the droplet size emitted from pMDIs: the addition of dissolved $\mathrm{CO}_{2}$ to HFA-134 and ethanol blend. After dose actuation, the bursting of the $\mathrm{CO}_{2}$ bubbles or "the effervescent effect" that occurs within the emitted HFA/ethanol droplet will break up the generated droplets into smaller ones; this approach aims to increase the respirable fraction emitted from a conventional pMDI. ${ }^{47}$

\section{Inhalation aids}

Spacers and valved holding chambers (VHCs) are used with pMDIs to increase the efficiency of aerosol delivery. A spacer is a tube or extension device that is placed at the interface between the patient and the pMDI. VHCs such as AeroChamber Plus ${ }^{\circledR}$ Flow-Vu ${ }^{\circledR}$ have a one-way valve at the mouthpiece end to allow inhalation and prevent exhalation into the chamber. VHC enables the patient to breath from a "standing aerosol cloud" that does not require breath coordination. ${ }^{48,49}$ These inhalation aids reduce the speed of the emitted aerosol and allow for the evaporation of propellant from larger droplets reducing oropharyngeal deposition and increasing deep lung deposition. However, they can also reduce the doses delivered from pMDI due to electrostatic precipitation. ${ }^{50}$ Newer spacers and VHCs are made of 
anti-static polymers that minimize adherence of the emitted particles to the inner walls of the spacer. ${ }^{38}$ New generations of spacers can indicate whether the patient is inhaling correctly or not, such as those that whistle when the patient is inhaling too quickly. ${ }^{15}$

\section{Multi-dose liquid inhalers (Respimat $^{\circledR}$ Soft Mist ${ }^{\mathrm{TM}}$ inhaler)}

The Respimat ${ }^{\circledR}$ inhaler combines the advantages of pMDIs and nebulizers. It is a small, portable, hand-held inhaler with no need for power supply (like pMDIs) that slowly aerosolizes propellant free-drug solutions as a soft mist (like nebulizers), thus decreasing the chance for oropharyngeal deposition. Administration of one-half of the cumulative dose of ipratropium bromide and fenoterol hydrobromide by Respimat $^{\mathbb{R}}$ achieved the same therapeutic outcome as that of the full dose administered by pMDI to asthmatic patients. ${ }^{51}$ Dalby et al also showed that the oropharyngeal deposition of fenoterol was significantly reduced when administered by Respimat $^{\circledR}$ than by pMDIs, whereas a pMDI with a spacer had the lowest oropharyngeal deposition. However, Respimat ${ }^{\mathbb{R}}$ has achieved the highest concentration of fenoterol in both central and peripheral lung regions. ${ }^{52}$ Respimat $^{\circledR}$ is the least recommended inhaler for patients with good inspiratory flow rates $(>30 \mathrm{~L} / \mathrm{min}) .{ }^{53}$ Combivent $^{\circledR}$ Respimat $^{\circledR}$ was the first Respimat to be approved by Food and Drug Administration (FDA) as maintenance therapy for COPD. ${ }^{54}$

The drug solution for Respimat ${ }^{\circledR}$ is stored in a collapsible bag inside the cartridge which is loaded inside the device. The Respimat ${ }^{\circledR}$ device has a tension spring that when twisted at $180^{\circ}$, forces a metered volume of drug solution through a capillary tube into a micropump. Once the patient presses the dose release button, the energy released from the spring forces the dose into the "uniblock", the unique structural part of this device. The uniblock allows the drug solution to pass through very fine filter channels releasing two jet streams of drug solution, that converge creating a large fraction of respirable droplets with slow velocity. ${ }^{52}$

\section{Dry powder inhalers}

DPIs are portable devices that require minimum patient coordination between breathing and actuation of the device to deliver powder medications. DPI drug formulations have greater chemical stability than liquid formulations, but manufacturing powders with the appropriate characteristics for easy aerosolization and alveolar delivery is more complicated. ${ }^{55}$ Performance of DPIs depends on the powder formulation and on the design of the inhaler device.

\section{Formulation design for DPIs}

Traditional powder blends consist of micronized drug particles $(1-5 \mu \mathrm{m})$ blended with an inactive excipient (lactose, mannitol, trehalose, sucrose, sorbitol, glucose) of larger sizes $(40 \mu \mathrm{m}) .{ }^{56}$ Particle engineering approaches are also employed to produce particles using different core materials and more recently of only pure drug. ${ }^{57}$

Unoptimized powder blends can exhibit interparticulate cohesive forces (van der Waals forces, mainly), which cause particle aggregates, making powder dispersion very difficult. ${ }^{3}$ Drug carrier excipients added in appropriate sizes can reduce such cohesive forces, thus achieving a better flow and more uniform doses. ${ }^{56}$

\section{DPI designs}

The design of DPI heavily influences the performance of the device. To aerosolize the drug powder, individual particles are deagglomerated by external forces, which can be airflow shear or particle-particle, particle-device impaction. The Clickhaler, the Multihaler, and the Diskus are designed to feed the powder into a high speed airflow that splits particle agglomerates, thus achieving respirable particles. Other devices like the Turbuhaler and the Spinhaler depend on the impaction between particles and surfaces of the device to deagglomerate. ${ }^{58,59}$

A major challenge in DPI design is to balance between inhaler resistance and flow rate. In early DPIs, a rapid airflow was required to increase particle deagglomeration by creating more frequent and stronger impactions to achieve a higher fine particle fraction. However, a rapid airflow increases the chances of oropharyngeal deposition and reduces the dose delivered to the lungs. ${ }^{59,60}$ Moreover, high resistances are not suitable for asthma or COPD patients who already struggle to breathe.

\section{DPI classification}

DPIs can be classified by the number of doses the device can carry, the patient contribution to aerosolize the powder, or by the mechanism of powder dispersion.

By the number of doses, DPIs can be classified as single-unit dose, multi-unit dose, and multi-dose reservoirs (Figure 1). In single-dose DPIs, the dose is supplied in individual capsules. Before each administration, the patient has to load the device with one capsule for a single dose delivery. Single-dose DPIs can further be classified as disposable or reusable. ${ }^{61}$ Multi-unit dose DPIs use factory-metered and sealed doses packaged so that the device can hold multiple doses at the same time without having to be reloaded. 

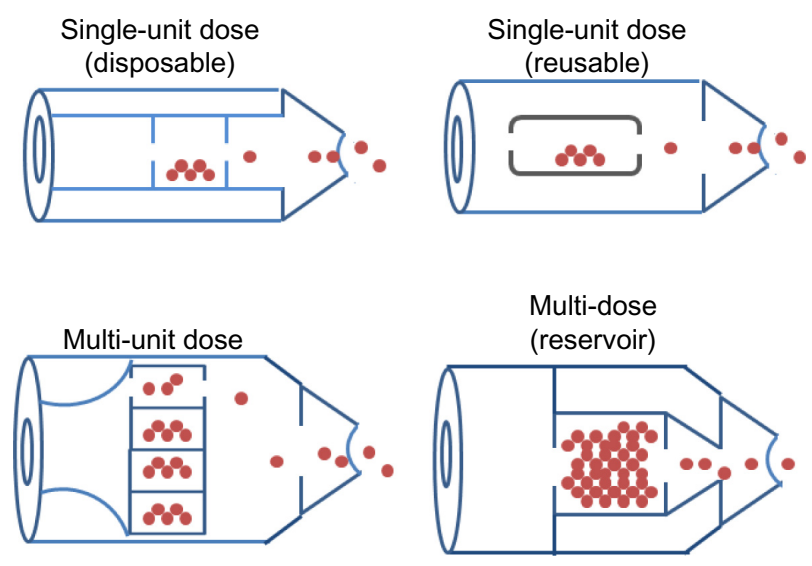

Figure I Dry powder inhaler devices classified by the number of doses.

Typically, the packaging consists of replaceable disks, cartridges, or strips of foil-polymer blister packaging. ${ }^{6,61,62}$ Multi-dose reservoir DPIs store the powder in bulk and have a built-in mechanism to meter individual doses upon actuation. Issues such as the dependence of the dose emission on the flow rate and the moisture uptake from patient exhalation or the environmental humidity into the reservoir, have yet to be addressed in these new devices. ${ }^{62,63}$

Based on the mechanism for powder aerosolization, DPIs can be classified as passively- or actively-actuated devices. The original passive DPI was a breath-actuated device, relying solely on the patient's inspiration to provide sufficient air flow for entrainment and de-aggregation of the formulation. Device actuation was intrinsically tied to the patient's inhalation, thus avoiding coordination issues associated with pMDIs. ${ }^{64,65}$ The first passive DPIs in the market were the Rotahaler ${ }^{\mathrm{TM}}$ and the Spinhaler ${ }^{\mathrm{TM}}$, which are single-dose devices. In the Rotahaler ${ }^{\mathrm{TM}}$, a capsule with the powder dose is loaded in the device. Upon actuation, the capsule gets pierced and an impeller rotates the powder released from the capsule by the inspiratory force of the patient. In the Spinhaler ${ }^{\mathrm{TM}}$, the capsule gets split into two halves and the dry powder is released and fluidized when the patient inhales. ${ }^{18}$

The main issue with passive DPIs was the lack of uniformity between the inspiratory force among patients with different age and disease state, as well as variation in the inspiratory force of the same patient. These variations significantly affect dose uniformity, even when the same device is used. Some devices are designed to reach optimum flow rate at a high pressure drop in order to reduce variability in the delivered dose. However, pediatric patients, elderly patients, and those with advanced respiratory diseases are not able to generate enough pressure drop to achieve the optimum flow rate. ${ }^{46,66} \mathrm{To}$ enhance their performance, newer versions of passive DPIs are being developed to solve these issues (Table 3).

Active (power assisted) DPI devices are designed with an internal energy source to aerosolize the powder bed in the DPI, so that dose administration is no longer dependent on the patient inspiratory flow rate. This energy source can be a battery, compressed gas, or a spring mechanism. In active devices, the powder is dispersed by vibration, gas discharge, or an impeller. The Spiros ${ }^{\mathrm{TM}}$ device (Dura, San Diego, CA, USA) has a battery-powered motor that disperses the powder by impaction of a rotating impeller to generate aerosol from

Table 3 Novel DPIs launched in the last 10 years

\begin{tabular}{|c|c|c|c|c|}
\hline Company & Device & Drug & Description & References \\
\hline \multirow[t]{2}{*}{$3 \mathrm{M}$} & 3М'м Taper & - & $\begin{array}{l}\text { A microstructured carrier tape delivers pure drug without } \\
\text { carrier excipients }\end{array}$ & 68 \\
\hline & $3 M$ Conix $^{\mathrm{TM}}$ & - & Reverse flow cyclone design for particle de-agglomeration & 69 \\
\hline $\begin{array}{l}\text { Almirall } \\
\text { Sofotec }\end{array}$ & Genuair $^{\circledR}$ & Aclidinium & Provides medium airflow resistance and locks-out when empty & 70 \\
\hline Chiesi & NEXThaler ${ }^{\circledR}$ & $\begin{array}{l}\text { Beclomethasone } \\
\text { and formoterol }\end{array}$ & DPI releases extra-fine particles with MMAD $<2 \mu \mathrm{m}$ & 71 \\
\hline Cipla & Revolizer & - & $\begin{array}{l}\text { Narrow capsule chamber for turbulence and long narrow mouth } \\
\text { piece for laminar airflow to reduce oropharyngeal deposition }\end{array}$ & 72 \\
\hline GSK & Ellipta & $\begin{array}{l}\text { Fluticasone } \\
\text { furoate }\end{array}$ & $\begin{array}{l}\text { Contains two separate blister strips and requires low } \\
\text { inspiratory flow rate }\end{array}$ & 73 \\
\hline $\begin{array}{l}\text { OPKO } \\
\text { Medical }\end{array}$ & Inspiromatic ${ }^{\mathrm{TM}}$ & - & $\begin{array}{l}\text { Works with extremely low inhalation flow rates and } \\
\text { incorporates a micro-pump and vortex to deliver fine particles }\end{array}$ & 74 \\
\hline Novartis & Breezhaler ${ }^{\circledR}$ & $\begin{array}{l}\text { Indacaterol/ } \\
\text { glycopyrronium }\end{array}$ & $\begin{array}{l}\text { Offers low resistance to be easily and efficiently used } \\
\text { by COPD patients. Patient can check if full dose is inhaled }\end{array}$ & 75 \\
\hline MannKind & $\begin{array}{l}\text { Dreamboat inhaler } \\
\text { Disposable Cricket }^{\mathrm{TM}} \\
\text { Technology }\end{array}$ & Insulin & $\begin{array}{l}\text { Simple, small and low cost passive DPI with unit dose cartridges } \\
\text { Small, low cost device for acute and short treatment durations }\end{array}$ & $\begin{array}{l}76 \\
76\end{array}$ \\
\hline Vectura & Aspirair & - & Mainly for systemic drug delivery through the lungs & 77 \\
\hline
\end{tabular}

Abbreviations: DPIs, dry powder inhalers; MMAD, mass median aerodynamic diameter; COPD, chronic obstructive pulmonary disease. 
the powder bed. The motor is activated by a very low breathing rate, which is convenient for asthmatic patients. Another source of powder dispersion, a piezoelectric polymer, was introduced in the Oriel device, a multi-dose blister DPI. When the patient inhales, an electrical impulse is sent to the blister, stimulating the piezoelectric polymer which is incorporated in each sealed blister to vibrate ejecting the powder into a flow stream. ${ }^{67}$ Although active DPIs appear easier to use than passive DPIs, none of these advanced devices has been marketed yet.

\section{Thermal vaporization aerosol devices}

The STACCATO ${ }^{\circledR}$ is a novel breath-actuated inhalation delivery system, which uses heat to vaporize a thin film of the drug, which later condenses in the lungs into droplets or particles depending on the nature of the drug. ${ }^{78}$ In that case, the drug is dissolved in volatile solvent/solvent mixture which is sprayed over a metal substrate such as zinc halides. The best drug candidates for such systems are those which are thermally stable and with low-melting points. The STACCATO ${ }^{\circledR}$ system can deliver the condensed aerosol deeply into the lungs with a fast onset of action making it suitable for systemic delivery. Nicotine is one example for drugs to be delivered through this aerosol device as a treatment for smoking withdrawal symptoms. ${ }^{79}$ The STACCATO ${ }^{\circledR}$ system is available in the market as Adasuve $^{\circledR}$, a recently FDA-approved DPI for agitation associated with schizophrenia or bipolar disorder in adults. ${ }^{80}$

\section{Future approaches}

The number of inhaler devices available in the market for inhaled therapies has increased significantly in the past decade. However, they have made modest differences in the clinical outcomes. Most of these newer devices are targeting the general adult population, but little to no attention had been placed in special patient populations such as the pediatric and geriatric populations. It will be desirable that pharmaceutical companies develop inhalers specific for each of these three distinct patient populations, considering their age and health condition in order to achieve the concept of "individualized inhaler".

Another issue to be considered is tailoring specific devices to the different therapeutic molecules being developed. Pulmonary drug delivery is an attractive route of administration for diverse entities including micro and macromolecules such as vaccines, DNA, cytokines, antibodies, and hormones. ${ }^{16}$ Therefore, it is essential that the hardware technology of inhalers meets the needs of the pulmonary delivery of such diverse molecules. Devices should be manufactured to ensure maximal stability for these highly sensitive molecules.

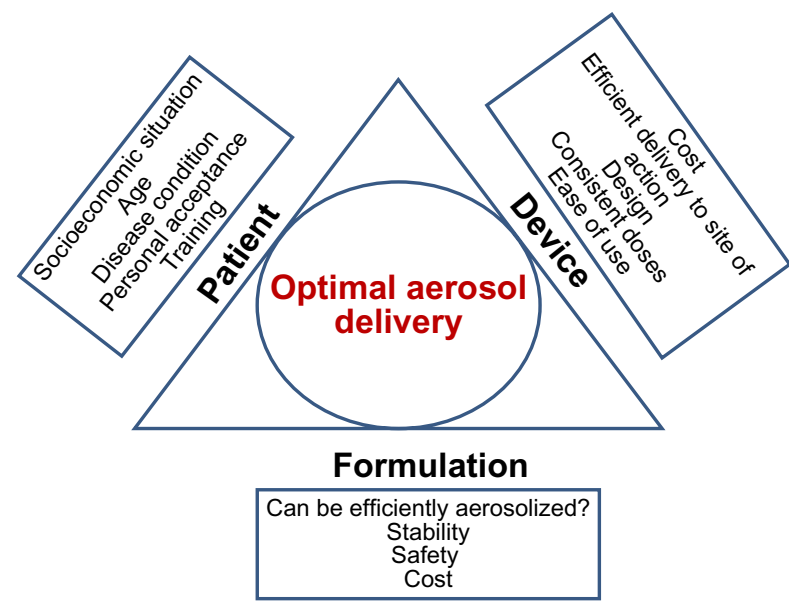

Figure $\mathbf{2}$ The diverse factors that can influence optimal aerosol delivery from inhalers.

Meeting future inhaler demands requires more sophisticated device design, but the inhalers should still be simple enough to be adequately used by the patients. Finally, it would be desirable that novel devices have low costs so that they can be afforded by all sectors of the general population.

\section{Conclusion}

Figure 2 depicts factors related to the patient, formulation, and device that should be addressed to achieve optimum aerosol delivery. The structure and design of inhaler have a major impact on the aerosol deposition to the lungs. An ideal inhaler should deliver precise and consistent doses to a targeted region in the lungs and maintain the stability of the delivered drugs. It is also desirable that devices are small and simple enough to be easily used by patients. DPIs are becoming more popular because of their ease of use and the powder stability. pMDIs are still facing challenges from the formulation and the design point of view. Nebulizers are being remodeled to broaden their applicability. In reality, there is no device that fulfills the myriad of requirements to deliver drugs with different physicochemical properties. The medical personnel must fully understand the capabilities of each inhaler and relate that to the needs of the patient, according to his health condition, to achieve the best therapeutic outcome.

\section{Disclosure}

The authors report no conflicts of interest in this work.

\section{References}

1. Anderson PJ. History of aerosol therapy: liquid nebulization to MDIs to DPIs. Respir Care. 2005;50(9):1139-1150.

2. Sanders M. Inhalation therapy: an historical review. Prim Care Respir J. 2007;16(2):71-81. 
3. Labiris NR, Dolovich MB. Pulmonary drug delivery. Part I: physiological factors affecting therapeutic effectiveness of aerosolized medications. Br J Clin Pharmacol. 2003;56(6):588-599.

4. Crompton G. A brief history of inhaled asthma therapy over the last fifty years. Prim Care Respir J. 2006;15(6):326-331.

5. Hess DR. Aerosol delivery devices in the treatment of asthma. Respir Care. 2008;53(6):699-723; discussion 723-725.

6. Chow AH, Tong HH, Chattopadhyay P, Shekunov BY. Particle engineering for pulmonary drug delivery. Pharm Res. 2007;24(3):411-437.

7. Ibrahim M, Garcia-Contreras L. Mechanisms of absorption and elimination of drugs administered by inhalation. Ther Deliv. 2013;4(8): 1027-1045.

8. Verma RK, Ibrahim M, Lucila G-C. Lung anatomy and physiology and their implications for pulmonary drug delivery. In: Nokhodchi A, editor. Pulmonary Drug Delivery: Advances and Challenges. Oxford, UK: John Wiley Publishers; 2014. inpress

9. Heyder J. Particle transport onto human airway surfaces. Eur J Respir Dis Suppl. 1982;119:29-50.

10. Hinds WC, Liu WC, Froines JR. Particle bounce in a personal cascade impactor: a field evaluation. Am Ind Hyg Assoc J. 1985;46(9): 517-523.

11. Zanen P, Go LT, Lammers JW. The efficacy of a low-dose, monodisperse parasympathicolytic aerosol compared with a standard aerosol from a metered-dose inhaler. Eur J Clin Pharmacol. 1998;54(1):27-30.

12. Farr SJ, Rowe AM, Rubsamen R, Taylor G. Aerosol deposition in the human lung following administration from a microprocessor controlled pressurised metered dose inhaler. Thorax. 1995;50(6):639-644.

13. Ari A, Restrepo RD. American Association for Respiratory C. Aerosol delivery device selection for spontaneously breathing patients: 2012 . Respir Care. 2012;57(4):613-626.

14. Newman SP. Aerosol deposition considerations in inhalation therapy. Chest. 1985;88(Suppl 2):152S-160S.

15. Laube BL, Janssens HM, de Jongh FH, et al. What the pulmonary specialist should know about the new inhalation therapies. Eur RespirJ. 2011;37(6):1308-1331.

16. Zhou QT, Tang P, Leung SS, Chan JG, Chan HK. Emerging inhalation aerosol devices and strategies: where are we headed? Adv Drug Deliv Rev. 2014;75C:3-17.

17. Darquenne C. Aerosol deposition in health and disease. J Aerosol Med Pulm Drug Deliv. 2012;25(3):140-147.

18. Dunbar CA, Hickey AJ, Holzner P. Dispersion and characterization of pharmaceutical dry powder aerosols. KONA Powder Part J. 1998;16: $7-45$.

19. Hess DR. Nebulizers: principles and performance. Respir Care. 2000;45(6):609-622.

20. Watts AB, McConville JT, Williams RO 3rd. Current therapies and technological advances in aqueous aerosol drug delivery. Drug Dev Ind Pharm. 2008;34(9):913-922.

21. Rubin BK, Williams RW. Emerging aerosol drug delivery strategies: from bench to clinic. Adv Drug Deliv Rev. 2014;75C:141-148.

22. Dolovich MB, Dhand R. Aerosol drug delivery: developments in device design and clinical use. Lancet. 2011;377(9770):1032-1045.

23. Davies LA, Nunez-Alonso GA, McLachlan G, Hyde SC, Gill DR. Aerosol delivery of DNA/liposomes to the lung for cystic fibrosis gene therapy. Hum Gene Ther Clin Dev. 2014;25(2):97-107.

24. Pitance L, Reychler G, Leal T, et al. Aerosol delivery to the lung is more efficient using an extension with a standard jet nebulizer than an open-vent jet nebulizer. J Aerosol Med Pulm Drug Deliv. 2013;26(4):208-214.

25. Skaria S, Smaldone GC. Omron NE U22: comparison between vibrating mesh and jet nebulizer. J Aerosol Med Pulm Drug Deliv. 2010;23(3):173-180.

26. Fischer A, Stegemann J, Scheuch G, Siekmeier R. Novel devices for individualized controlled inhalation can optimize aerosol therapy in efficacy, patient care and power of clinical trials. Eur J Med Res. 2009;14(Suppl 4):71-77.

27. Nikander K, Prince I, Coughlin S, Warren S, Taylor G. Mode of breathing-tidal or slow and deep-through the I-neb Adaptive Aerosol Delivery (AAD) system affects lung deposition of (99m)Tc-DTPA. J Aerosol Med Pulm Drug Deliv. 2010;23(Suppl 1):S37-S43.
28. Sabato K, Ward P, Hawk W, Gildengorin V, Asselin JM. Randomized controlled trial of a breath-actuated nebulizer in pediatric asthma patients in the emergency department. Respir Care. 2011;56(6):761-770.

29. Luisetti M, Kroneberg P, Suzuki T, et al. Physical properties, lung deposition modeling, and bioactivity of recombinant GM-CSF aerosolised with a highly efficient nebulizer. Pulm Pharmacol Ther. 2011;24(1):123-127.

30. CompAIR NE-C801. OMRON Healthcare Europe BV; August 19, 2014. Available from: http://www.omron-healthcare.com/eu/en/our-products/ respiratory-therapy/compair-ne-c801.

31. Geller DE, Kesser KC. The I-neb adaptive aerosol delivery system enhances delivery of alpha1-antitrypsin with controlled inhalation. J Aerosol Med Pulm Drug Deliv. 2010;23(Suppl 1):S55-S59.

32. Najlah M, Parveen I, Alhnan MA, et al. The effects of suspension particle size on the performance of air-jet, ultrasonic and vibrating-mesh nebulisers. Int J Pharm. 2014;461(1-2):234-241.

33. Govoni M, Poli G, Acerbi D, et al. Pharmacokinetic and tolerability profiles of tobramycin nebuliser solution $300 \mathrm{mg} / 4 \mathrm{ml}$ administered by PARI eFlow $\left({ }^{\circledR}\right)$ rapid and PARI LC Plus $\left({ }^{\circledR}\right)$ nebulisers in cystic fibrosis patients. Pulm Pharmacol Ther. 2013;26(2):249-255.

34. Hodson ME, Gallagher CG, Govan JR. A randomised clinical trial of nebulised tobramycin or colistin in cystic fibrosis. Eur Respir J. 2002;20(3):658-664.

35. Vaswani SK, Creticos PS. Metered dose inhaler: past, present, and future. Ann Allergy Asthma Immunol. 1998;80(1):11-19; quiz 19-20.

36. Smyth HD. The influence of formulation variables on the performance of alternative propellant-driven metered dose inhalers. Adv Drug Deliv Rev. 2003;55(7):807-828

37. Cummings RH. Pressurized metered dose inhalers: chlorofluorocarbon to hydrofluoroalkane transition-valve performance. J Allergy Clin Immunol. 1999;104(6):S230-S236.

38. Stein SW, Sheth P, Hodson PD, Myrdal PB. Advances in metered dose inhaler technology: hardware development. AAPS PharmSciTech. 2014;15(2):326-338

39. Smyth HD. Propellant-driven metered-dose inhalers for pulmonary drug delivery. Expert Opin Drug Deliv. 2005;2(1):53-74.

40. Newman SP. Principles of metered-dose inhaler design. Respir Care. 2005;50(9):1177-1190.

41. Li HY, Seville PC. Novel pMDI formulations for pulmonary delivery of proteins. Int J Pharm. 2010;385(1-2):73-78.

42. Bains BK, Birchall JC, Toon R, Taylor G. In vitro reporter gene transfection via plasmid DNA delivered by metered dose inhaler. J Pharm Sci. 2010;99(7):3089-3099.

43. Hoe S, Boraey MA, Ivey JW, Finlay WH, Vehring R. Manufacturing and device options for the delivery of biotherapeutics. J Aerosol Med Pulm Drug Deliv. 2014;27(5):315-328.

44. Li YNL, Liu M, Webb K. Addressing China's growing need for inhaled drugs: development strategies for marketing, distribution, and regulation. In: Dalby RN, Byron PR, Peart J, Suman JD, Farr S, Young PM, editors. Respiratory Drug Delivery. River Grove, IL: Davis Healthcare International Publishing, LLC; 2014:131-142.

45. Crompton GK. Breath-activated aerosol. Br Med J. 1971;2(5762): 652-653.

46. Lenney J, Innes JA, Crompton GK. Inappropriate inhaler use: assessment of use and patient preference of seven inhalation devices. EDICI. Respir Med. 2000;94(5):496-500.

47. Kelkar MS, Dalby RN. Effervescent aerosols: a novel formulation technology for pressurized metered dose inhalers. In: Dalby RN, Byron PR, Peart J, Suman JD, Farr S, Young PM, editors. Respiratory Drug Delivery. River Grove, IL: Davis Healthcare International Publishing, LCC; 2014:669-672.

48. Steckel H, Muller BW. Metered-dose inhaler add-on devices: an in vitro evaluation of the BronchoAir inhaler and several spacer devices. JAerosol Med. 1998;11(3):133-142.

49. Terzano C, Mannino F. Probability of particle and salbutamol deposition in the respiratory tract: comparison between MDI and Autohaler. Monaldi Arch Chest Dis. 1996;51(3):236-242. 
50. Wildhaber JH, Waterer GW, Hall GL, Summers QA. Reducing electrostatic charge on spacer devices and bronchodilator response. Br J Clin Pharmacol. 2000;50(3):277-280.

51. Kunkel G, Magnussen H, Bergmann K, et al. Respimat (a new soft mist inhaler) delivering fenoterol plus ipratropium bromide provides equivalent bronchodilation at half the cumulative dose compared with a conventional metered dose inhaler in asthmatic patients. Respiration. 2000;67(3):306-314.

52. Dalby RN, Eicher J, Zierenberg B. Development of Respimat ${ }^{\circledR}$ Soft Mist Inhaler and its clinical utility in respiratory disorders. Med Devices. 2011;4:145-155.

53. Lavorini F. The challenge of delivering therapeutic aerosols to asthma patients. ISRN Allergy. 2013;2013:102418.

54. US Food and Drug Administration. FDA Approves Combivent Respimat (Ipratropium Bromide and Albuterol Sulfate) Inhalation Spray. Washington DC: US Department of Health and Human Services; [updated October 7, 2011/October 2, 2014].

55. Sanchis J, Corrigan C, Levy ML, Viejo JL, Group A. Inhaler devices from theory to practice. Respir Med. 2013;107(4):495-502.

56. Lippmann M, Yeates DB, Albert RE. Deposition, retention, and clearance of inhaled particles. Br J Ind Med. 1980;37(4):337-362.

57. Chan JG, Duke CC, Ong HX, et al. A novel inhalable form of rifapentine. J Pharm Sci. 2014;103(5):1411-1421.

58. Begat P, Morton DA, Shur J, Kippax P, Staniforth JN, Price R. The role of force control agents in high-dose dry powder inhaler formulations. J Pharm Sci. 2009;98(8):2770-2783.

59. Islam N, cleary MJ. Developing an efficient and reliable dry powder inhaler for pulmonarydrug delivery-a review for multidisciplinary researchers Medical engineering and physics. 2012;34(4):409-427.

60. Timothy Crowder MD. Science and technology of dry powder inhalers In: Smyth HDC, Hickey AJ, editors. Controlled Pulmonary Drug Delivery. New York: Springer; 2011;203-222.

61. Bell JH, Hartley PS, Cox JS. Dry powder aerosols. I. A new powder inhalation device. J Pharm Sci. 1971;60(10):1559-1564.

62. Ashurst II, Malton A, Prime D, Sumby B. Latest advances in the development of dry powder inhalers. Pharm Sci Technolo Today. 2000;3(7):246-256.

63. Atkins PJ. Dry powder inhalers: an overview. Respir Care. 2005;50(10): 1304-1312; discussion 1312.

64. Tiddens HA, Geller DE, Challoner P, et al. Effect of dry powder inhaler resistance on the inspiratory flow rates and volumes of cystic fibrosis patients of six years and older. J Aerosol Med. 2006;19(4):456-465.

65. Dunbar CA, Concessio NM, Hickey AJ. Evaluation of atomizer performance in production of respirable spray-dried particles. Pharm Dev Technol. 1998;3(4):433-441.

66. Labiris NR, Dolovich MB. Pulmonary drug delivery. Part II: the role of inhalant delivery devices and drug formulations in therapeutic effectiveness of aerosolized medications. Br J Clin Pharmacol. 2003;56(6): 600-612.

67. Crowder T, Hickey A, Warden J, inventor. Dry powder inhalers, related blister devices, and associated methods of dispensing dry powder substances and fabricating blister packages. United States patent US 20040025877 A1. February 12, 2004.
68. Systems MDD. Comparative Performance of the 3MTM Taper Dry Powder Inhaler Device; 2011. Available from: http://solutions.3m. com/3MContentRetrievalAPI/BlobServlet?locale $=$ en $\_$WW\&lmd $=$ $1314027541000 \&$ assetId $=1273684150144 \&$ asset Type $=$ MMM_ Image\&blobAttribute=ImageFile. Accessed October 2, 2014.

69. Systems MDD. Developing an Efficient Dry Powder Inhaler 3M Conix ${ }^{\mathrm{TM}}$ DPI; 2011. Available from: http://solutions.3m. com/3MContentRetrievalAPI/BlobServlet?lmd=1301085878000\&lo cale=en_WW\&assetType=MMM_Image \&assetId $=1273680315945 \&$ blobAttribute=ImageFile. Accessed October 2, 2014.

70. Chrystyn H, Niederlaender C. The Genuair(R) inhaler: a novel, multidose dry powder inhaler. Int J Clin Pract. 2012;66(3):309-317.

71. Kanniess F, Scuri M, Vezzoli S, Francisco C, Petruzzelli S. Extrafine beclomethasone/formoterol combination via a dry powder inhaler $\left(\right.$ NEXThaler ${ }^{\mathbb{R}}$ ) or pMDI and beclomethasone monotherapy for maintenance of asthma control in adult patients: a randomised, double-blind trial. Pulm Pharmacol Ther. 2014.

72. Geena M, Pragati R, Vrinda M, Bhumika A, Jaideep AG. Revolizer ${ }^{\mathbb{}}$ : the next generation novel single dose dry powder inhaler. In: Dalby RN, Byron PR, Peart J, Suman JD, Farr S, Young PM, editors. Respiratory Drug Delivery. River Grove, IL: Davis Healthcare International Publishing, LCC; 2014:401-404.

73. Svedsater H, Dale P, Garrill K, Walker R, Woepse MW. Qualitative assessment of attributes and ease of use of the ELLIPTA dry powder inhaler for delivery of maintenance therapy for asthma and COPD. BMC Pulm Med. 2013;13:72.

74. OPKO. INSPIROMATICTM. Available from http://investor.opko.com/ releasedetail.cfm?ReleaseID $=850077$. May 22, 2014. Accessed at November 18, 2014

75. Vectura. Positive Results for Once-Daily Ultibro ${ }^{\circledR}$ Breezhaler $^{\circledR}$ Versus Combination Therapy (Tiotropium Plus Formoterol); 2014 [updated May 21, 2014; cited October 2, 2014]. Available from: http://www. vectura.com/media/press-releases/2014/21-may-2014a.aspx. Accessdate 10.02.2014

76. ManKind Corporation. Patient-Focused Dry Powder Inhalers; Available from: http://www.mannkindcorp.com/Collateral/Documents/EnglishUS/102LR-DeviceTechTeaser-01.19.11.pdf. Accessed October 2, 2014. published at 2011

77. Vectura. Vectura Announces CE Mark for Aspirair ${ }^{\circledR}$ Inhaler; 2007. Available from: http://www.vectura.com/media/press-releases/ archive/2007/2007-01-24.aspx. Accessed October 2, 2014.

78. Cipolla DC, Gonda I. Formulation technology to repurpose drugs for inhalation delivery. Drug Discov Today: Ther Strateg. 2011;8(3-4): $123-130$.

79. Simis K, Lei M, Lu AT, et al. Nicotine aerosol generation from thermally reversible zinc halide complexes using the Staccato system. Drug Dev Ind Pharm. 2008;34(9):936-942.

80. Teva Pharmaceuticals. Product Monograph Adasuve (Loxapine) Inhalation Powder. [updated October 02, 2014]. Available from: http:// adasuve.com/PDF/Adasuve_Formulary_kit_Monograph.pdf. published at May 21, 2014
Medical Devices: Evidence and Research

\section{Publish your work in this journal}

Medical Devices: Evidence and Research is an international, peerreviewed, open access journal that focuses on the evidence, technology, research, and expert opinion supporting the use and application of medical devices in the diagnosis, treatment and management of clinical conditions and physiological processes. The identification of novel

\section{Dovepress}

devices and optimal use of existing devices which will lead to improved clinical outcomes and more effective patient management and safety is a key feature. The manuscript management system is completely online and includes a quick and fair peer-review system. Visit http://www. dovepress.com/testimonials.php to read real quotes from authors. 